www. revistadyo. com

\title{
Sustainability and the Sharing Economy: Modelling the Interconnections
}

\author{
Meisam Ranjbari, Gustavo Morales-Alonso, Zahra Shams Esfandabadi, Ruth Carrasco-Gallego
}

Recibido: 15 de Octubre de 2018 / Aceptado: 11 de Noviembre de 2018

\begin{abstract}
Advances in technology have led to the rise of sharing economy, which has become a strong competitor for capitalist companies in various fields. In addition to the economic aspects of such phenomenon, the activities of the sharing economy can have social and environmental impacts, which brings sustainability pillars into mind. In this paper, based on the system thinking approach, a causal loop diagram that is a part of system dynamics modelling is applied for visualizing the relationships between sharing economy and sustainability pillars. The reinforcing and balancing loops modelled show the dynamics in the system, which help decision makers to gain a deeper and more accurate understanding of the current and potential future mutual interactions between the sharing economy and sustainability.
\end{abstract}

\section{Keywords}

Triple Bottom Lines; Online Platforms; Causal Loop Diagram (CLD); System Dynamics (SD); Sustainability Paradox.

\section{Introduction}

The rise of Sharing Economy (SE) in the recent few years has created a platform for a strong competition among businesses in various fields, and has started changing the consumption pattern of the people. Airbnb in accommodation sector, Uber and Lyft in transportation sector and Funding Circle, LendingClub, TransferWise and Prosper in finance or banking sector are considered as a few examples, which have disrupted the businesses of traditional capitalist companies in hoteling, mobility and banking industry, respectively. Online platforms can be introduced as the main infrastructure of the SE (Mair \& Reischauer, 2017; Michelini, et al., 2018), and smart phones and the new mobile apps have helped SE to expand rapidly in various fields. No transfer of ownership, temporary access, and redistribution of material goods or less tangible assets are the characteristics to be named for the SE (Kathan, et al., 2016). Although a generally accepted definition does not exist for the SE, yet (Michelini et al., 2018; Cho et al, 2017; Novikova, 2017; Rahim et al., 2017),

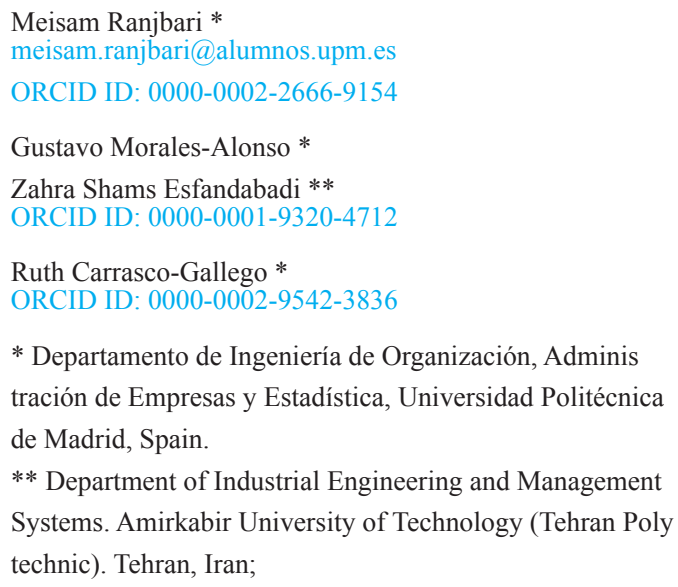

Ranjbari et al. provide a comprehensive definition of SE and defines SE as "an economic system, whose intermediary companies utilize online platforms to facilitate and lower the cost of the for-profit transactions of giving temporary access - without the transfer of ownership — to idle resources of consumers in the peer-to-peer networks that it has created, because of the trust built among its members, who may be individuals or businesses".

This subject has attracted the attention of many scholars and various studies have been conducted in this regard. Many papers have been written regarding the activities of the companies that are claimed to be active in the SE, and a significant number of such papers, including Frenken \& Schor (2017), Stanković et al. (2016), Heinrichs (2013), Muñoz \& Cohen (2017), Goudin (2016) Murillo et al. (2017), Roh (2016) and Stephany (2016), have analyzed SE activities from the standpoint of the triple bottom lines. Frenken and Schor (2017) conducted a valuable assessment of the SE platforms in terms of the economic, social and environmental impacts considering both car and accommodation sharing. In addition, some papers notice the concept of sustainability by considering factors such as more efficient utilization of the resources, creating social capital, reducing economic activities, lowering environmental pollutions and empowering ordinary people (Kosintceva, 2016; Martin, 2015; Muñoz $\&$ Cohen, 2017). Heinrichs (2013) expects SE activities to build "a potential new pathway to sustainability" and Liu and Yang (2018) believe that one way towards the adoption of sustainable lifestyles is to develop SE activities. Besides, some papers have focused on a specific field of activity in the $\mathrm{SE}$ and have analysed it from sustainability viewpoint. For instance, Jin et al. (2018) provided a systematic review of the existing literature regarding the impact of ride-sourcing on the efficiency, equity, and sustainability of urban development and Bekawade and Ingale (2016) focused on Smart City-Scale Taxi Ridesharing. 
Having in mind the potential relationships between the SE variables and the sustainability elements, the present research aims at revealing the complexity behind the sustainability of SE activities, and tries to answer "how SE and sustainability are interconnected?". Therefore, considering three main fields of transportation, accommodation and finance for SE activities, the effective variables in this system are identified and their relationships with the variables within the three main pillars of sustainability are illustrated using system dynamics causal loop diagram (CLD).

\section{Methodology}

Sharing economy affects not only the economy of the society, but also its other sections, such as its environment and the social lives of the people. Therefore, a complex system is formed when we think of the relationships between its underlying internal and external factors. If considering the SE as a subsystem and sustainability as another subsystem, there are mutual relationship between their underlying elements. In addition, the subsystems within sustainability, which include its main pillars, are affected by each other. However, considering all the relationships between the effective variables in such complex system at once is almost impossible.

This research aims at revealing the complexity behind the sustainability of SE activities. Therefore, we apply system thinking theory to help explain the structure and dynamics underlying the SE activities regarding the triple bottom lines. To do this, the first two steps of five System Dynamics (SD) modelling steps- including (1) boundary selection; (2) dynamics hypothesis; (3) formulation; (4) testing; and (5) policy formulation and evaluation (Sterman, 2000)- are taken, which can be further extended and modelled for simulation.
This methodology explains that the counterintuitive or non-intuitive behaviour of the system lies not only on the system variables, but also on the structure of the system and the way the variables interact. So, its objective is to provide an understanding of the causal relationships and the feedback loops in a complex system.

In order to portray the feedback structure between variables, CLD is used, which is a comprehensive thinking tool (Jittrapirom et al., 2017). CLD illustrates the cause and effect relationships between the variables and shapes the system behaviour over time. It develops an endogenous description of the system behaviour that helps to identify the system archetypes and leverage points to be applied in policy making (Maani and Cavana, 2007). Besides, CLD challenges the established mental models and test assumptions, which can result in achieving important and sometimes counter-intuitive insights about the structure and behaviour of the system (Hovmand, 2014) and when it is applied in a systematic manner, it helps decision making and enables more effective problem solving (Jittrapirom et al., 2017). It is worthwhile mentioning that CLD always reflects the perspective of its constructor and the theories forming its basis. (Jittrapirom et al., 2017).

Fig. 1 illustrates the subsystems diagram, which shows the overall architecture of the system described. This diagram is useful for visualizing the main subsystems and their relationship with each other (Sterman, 2000). In fact, a model based on CLD is implemented in this research to get a deeper insight into the complex system comprising of SE and sustainability subsystems. This diagram is useful in illustrating how different variables in a system are interrelated and permits qualitative mapping of an identified system.

Figure 1 The relationships between the main sub-systems of the model

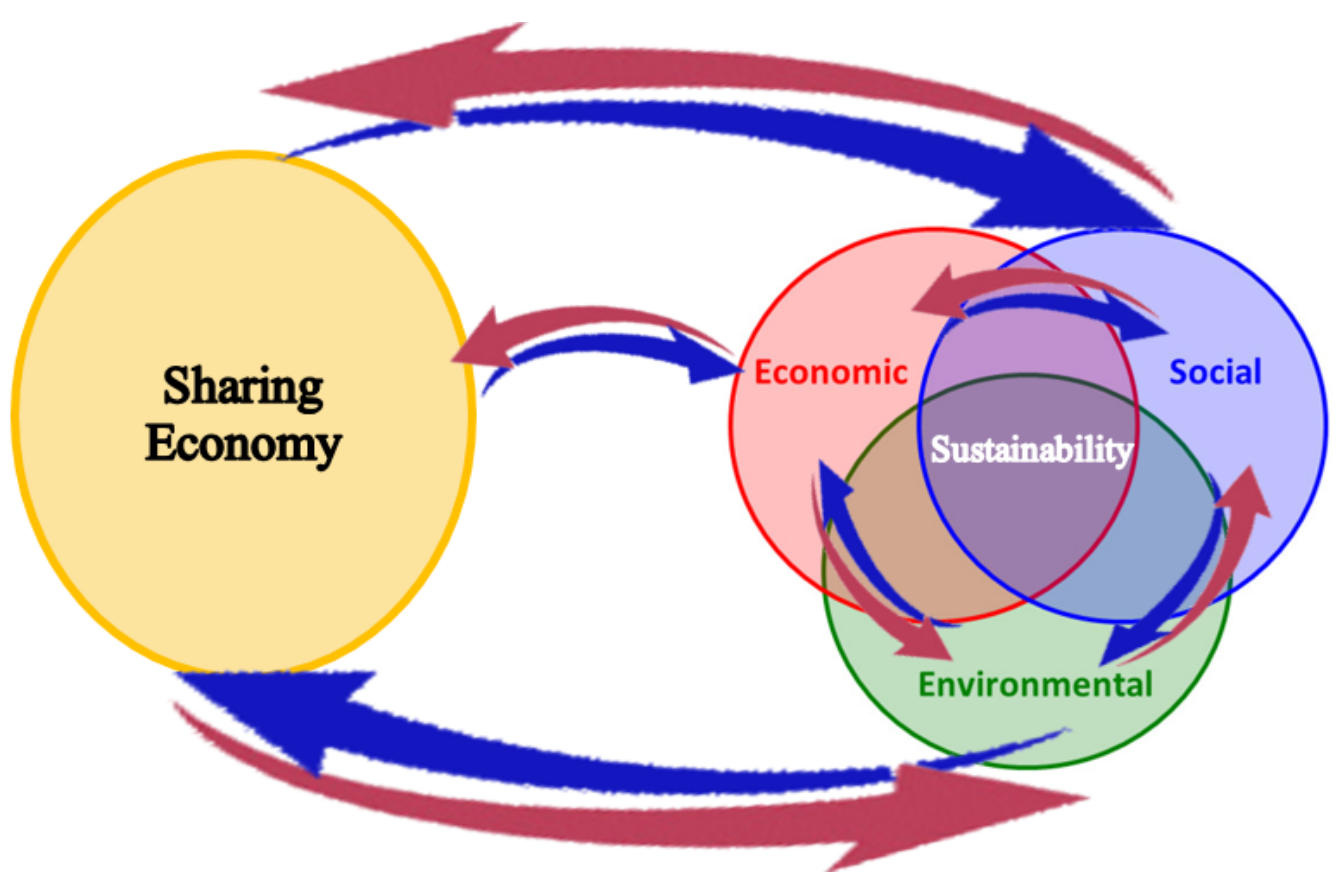


In order to develop the CLD, the Vensim PLE $\AA$ software is utilized and the main variables of the system was extracted from the literature.

\section{Results and Discussion}

Based on the studies conducted on the relationships between the SE and different aspects of sustainability, the CLD of the system is developed. In order to better focus on the relationships between the pillar subsystems and the SE, we consider them in the following three sub-sections. For brevity reasons, not all feedback loops within and between subsystems are presented in this paper. Instead, the system structure in the CLD which reflect the system archetypes are discussed.

\subsection{Subsystem of the Environmental Pillar}

Frenken and Schor (2017) believe that sharing is eco-friendly because it decreases the demand for construction or manufacturing new goods. However, the rebound effect and sustainability paradox in this regard (Verboven and Vanherck, 2016) should not be neglected. Sustainability paradox refers to the increase in consumption due to societal and economic factors, while there is an environmental need for reducing the consumption (Pater, 2015). Verboven and Vanherck (2016) define this paradox as "the contradiction between the obvious positive effects of a sustainable business model and the often less visible or ignored negative externalities, including the rebound-effect, both on behavioural as on systemic level, associated with the transition from the old to the novel model". Therefore, the contradictions regarding the general environmental effects of the SE lead us towards not trusting the claim that SE activities are environmentally sustainable (Murillo et al., 2017). However, Geissinger et al. (2019) believe that "the sharing economy does not drive a sustainability movement, but rather adjusts to those circumstances it aims to become a part of".

In addition, with regard to the transportation, when the drivers consider shared transportation as their second or complementary job, the number of pollutant cars in the street goes up, which leads to more air and water resources pollution. On the other hand, if such ride-sourcing is well organized, the number of cars with only one or two passengers decrease, and both the traffic and pollution decline. In case more electricity or renewable energy consuming cars are manufactured, the pollution can be reduced, due to less fossil fuel consumption.

Fig. 2 illustrates two balancing (negative) loops within the sustainability environmental pillar, shown by B1 and B2 and also a reinforcing loop, shown by R1.

Loop R1 (reinforcing loop) points out the rebound effect that happens regarding the SE activities. When people become more interested in SE activities due to its visible and direct advantages, such as its positive effects on the environment (in this loop) or decrease in the prices (in the economic pillar), the demand for production of goods or construction of accommodations for being shared goes up. In addition, the development of shard financial services enables more people for buying cars or accommodations and therefore, leads to increase in demand. The increase in the production of goods (or constructing accommodations) leads to more pollution generation. Therefore, albeit people were looking for more benefit, they face more challenges.
Figure 2 Archetype of the subsystem of sustainability environmental pillar

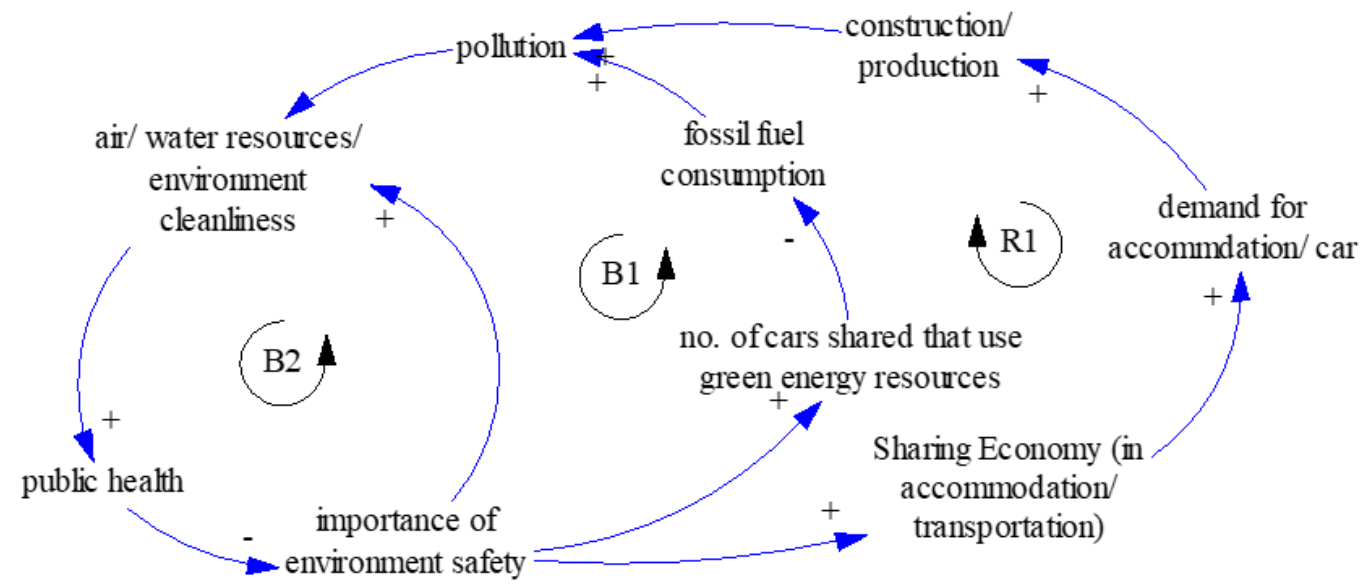


Loop B1 (balancing loop) refers to the decrease in pollution caused by the increase in the number of renewable energy consuming cars, which then leads to public health improvement. However, when people are in a good state of health, they mostly become negligent about the importance of environment safety, and may be interested in buying fossil fuel consuming cars if two fossil and non-fossil fuel cars are similar in other aspects. Besides, referring to Loop B2 (balancing loop), the negligence resulting from a good health status in the society leads people to be indifferent regarding the cleanliness of the environment and they may pollute the environment by various activities, too. Such pollutions lead the public health to face danger. When health status in a society is not good, people become more conscious regarding the importance of environmental cleanliness. Therefore, if they try to keep their environment clean and safe, public health will improve.

Hence, effective policy making by the government regarding keeping people aware of the importance of environmental safety and also providing attractive conditions for buying green energy consuming cars are highlighted by this figure. In addition, strategic decisions should be made to avoid the negative outcomes of rebound effect in the society.

\subsection{Subsystem of the Social Pillar}

Economic activities in the society have impacts on human lives. Therefore, SE activities in various fields can directly or indirectly affect social variables, and considering the social pillar subsystem, various loops can be found which are related to the impacts of SE activities. Fig. 3 illustrates seven of these loops.

According to Loop R8, which constitutes the perimeter of the biggest circle in Fig. 3, when probability for more social relationships are increased, the general satisfaction of the users goes up and this leads into more attraction of the immigrants, which then increases the population and again, probability for more social relationships are increased.
Loops R2-R4 and R9-R14 point out trust building as a result of increased probability for more social relationships that are provided by online platforms in SE. In fact, social trust is more important than any other market force in the SE transactions (Ranjbari et al., 2918). Paundra, et al. (2017) believes that "information technology has enabled the widespread adoption of Sharing Economy principles by allowing individuals to communicate, coordinate and build trust with others in a large public arena". Such trust motivates people to participate in sharing activities and therefore, to share their idle capacity or put their money to be used as loans for personal purposes or small new businesses. When people participate in such activities, they are satisfied with themselves and this feeling would increase the general satisfaction of the users in the society. Where general satisfaction of the users in the society or community improves, both national and international tourists and also immigrants are motivated to visit or live there. Therefore, the population grows, which results in higher probability of social relationships, leading to more social trust.

To follow the mentioned loops on the figure, starting from population that leads to changes in probability for more social relationships and then, trust building, loop R2 goes rough loans for small new businesses resulting in self-satisfaction, general satisfaction of the users and attraction for immigrants that affect population. Loops R9 and R12 follows the same direction up to the variable "attraction for tourists", then, R9 goes through the number of international tourists, while R12 goes through number of national tourists, which both lead to a change in the population. Loops R3 and R4 follow the same direction as R2 but pass "using idle capacity" and "loans for personal purposes" instead of loans for small new businesses. Loops R10 and R13 are similar to R9 and R12, respectively, but they pass "using idle capacity" instead of "loans for small new businesses. Besides, loops R11 and R14 pass the same direction as R9 and R12, respectively, but they consider loans for personal purposes instead of that for small new businesses. 
Figure 3 Archetype of the subsystem of sustainability social pillar

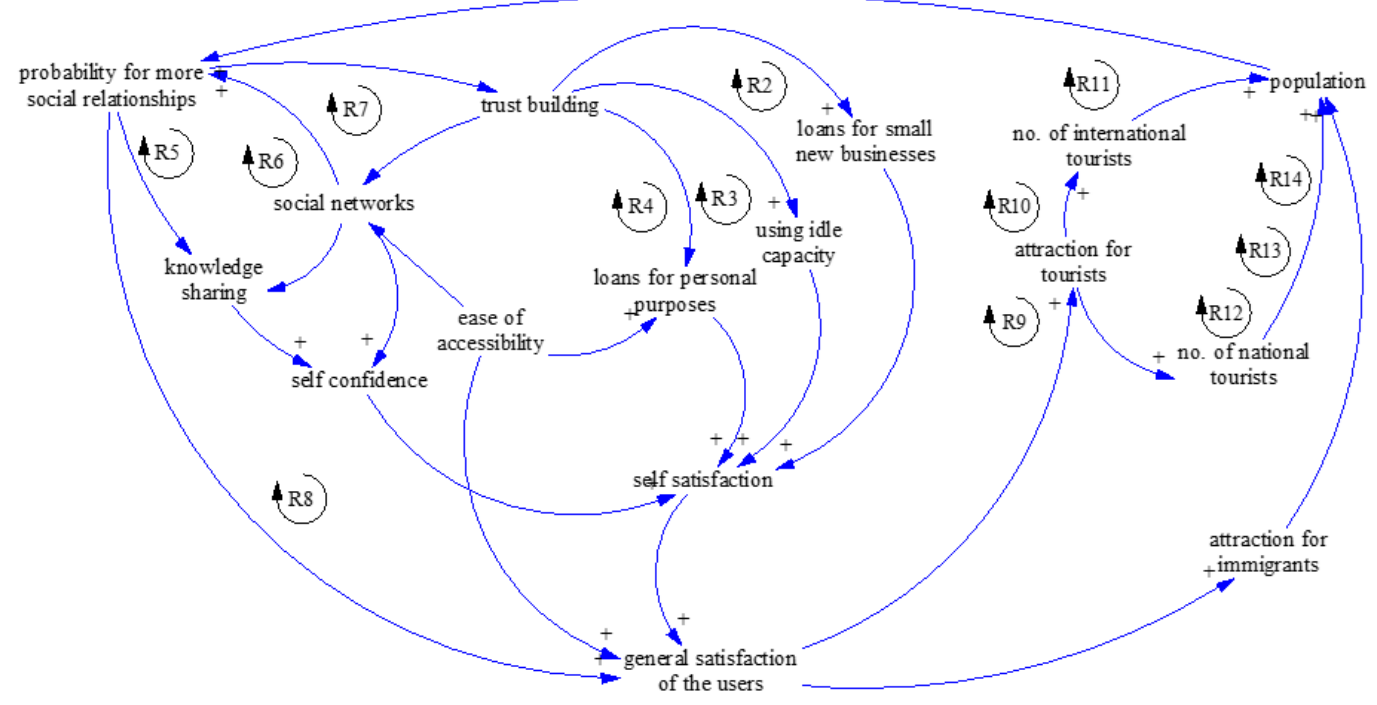

Being a part of a social network and also sharing knowledge improves the self-confidence of the people. This is considered in loops R5, R6 and R7, where probability for more social relationships leads to direct knowledge sharing or indirect knowledge sharing through social networks that are created based on the built trust among various participants in SE. To clarify the loops, loop R7 is built of 3 variables: probability for more social relationships, trust building and social networks. This is while loop R6 follows probability for more social relationships, trust building, social networks, self-confidence, general satisfaction of the users, attraction for immigrants and population and then returns back to probability for more social relationships. It can also consider attraction for tourists followed by number of national or international tourists, which introduces 2 new loops. However, to avoid confusion on the figure, we avoid numbering new loops. Finally, loop R5 moves from probability for more social relationships to knowledge sharing and self-confidence, and follows the same path as R6. Similarly, new loops can be introduced on the figure, but we avoid numbering them.

In general, SE online platforms and the rating systems provided through them pave the ground for more trust and social relationships among the participants in the SE. This can be considered as a good outcome of the SE activities, which requires the attention of policy makers in various levels to keep the health and safety of such relationships.

\subsection{Subsystem of the Economic Pillar and Sharing Economy}

Since the nature of sharing economy is of economic activities, it is intertwined in the economic pillar of sustainability. Hence, the subsystem of SE and the subsystem of economic pillar of sustainability are explained together in this section.
As stated in section 1, when identifying the SE variables in this research, three fields of activity were considered: ride-sourcing consisting of car-sharing and ridesharing; accommodation consisting of personal accommodations and work spaces; and finance consisting of loans provided for individuals and loans for entrepreneurs and small businesses. All of these fields would affect each other, and also other businesses in the society; and in addition to the economic effects, social and environmental aspects of the society would be affected by them (as stated in subsections 3.1 and 3.2).

If considering the economic variables of the CLD presented in Fig. 4, various reinforcing and balancing loops exist between the subsystems of the model, both between variables within each subsystem and among the subsystems. However, it is not possible to go over all of them, as the number of these loops are very high (it exceeds 1500).

As illustrated in Fig. 4, most of the activities taking place in SE are related to economic aspect of sustainability. The more SE activities take place, the more competition regarding price and quality is formed between the related companies. This results in higher quality business activities in a competitive market. However, considering profit margins, there would be a minimum for the prices charged and of course, there would be a limitation regarding the demand for such services, because the population growth rate is not as high as the growth rate of such businesses. Therefore, this positive relationship would not lead to an everlasting positive effect, as there is a balancing force against it.

In general, $\mathrm{SE}$ companies are becoming great competitors for the capitalist companies in different fields, as stated in some articles (such as Guttentag (2015)). However, if this competition is well directed and the required law for the progress of overall economic activities are set, the overall result would be to the benefit of the whole society. 
Considering the whole model, two balancing loops that connect SE with all three pillars of sustainability are the loops that stress on the relationship between the general satisfaction of the users affecting by economic outcomes of the SE, which then leads to more environmental concerns. Based on this loop, when people use their investments or loans provided by shared financial services for buying a car or house, the potential for idle capacity is increased and therefore, number of shared accommodations or ride-sourcing goes up. The more income they earn from sharing this idle capacity, the more they become interested in expanding the idle capacity to generate income; therefore, demand for construction of buildings and demand for car manufacturing increases, which will result in more pollution. When the cleanliness of the air or water resources and environment faces danger, the general satisfaction of the users decreases and therefore, the number of immigrants decrease. Such a decline would affect population which create the demand for temporary accommodation or car-sharing. If there is a decline in the demand for using idle resources, the income of the owners of idle capacity decrease and they would have less saving for investment.

Many more positive and negative loops can be found in the model that we are not going to discuss here for brevity. However, such reinforcing and balancing loops in the model form the overall mechanism of the interaction between different elements of the system, which can provide a good insight for people, legal authorities and various businesses for making decisions.
Figure 4 System dynamics CLD of the SE and sustainability pillars

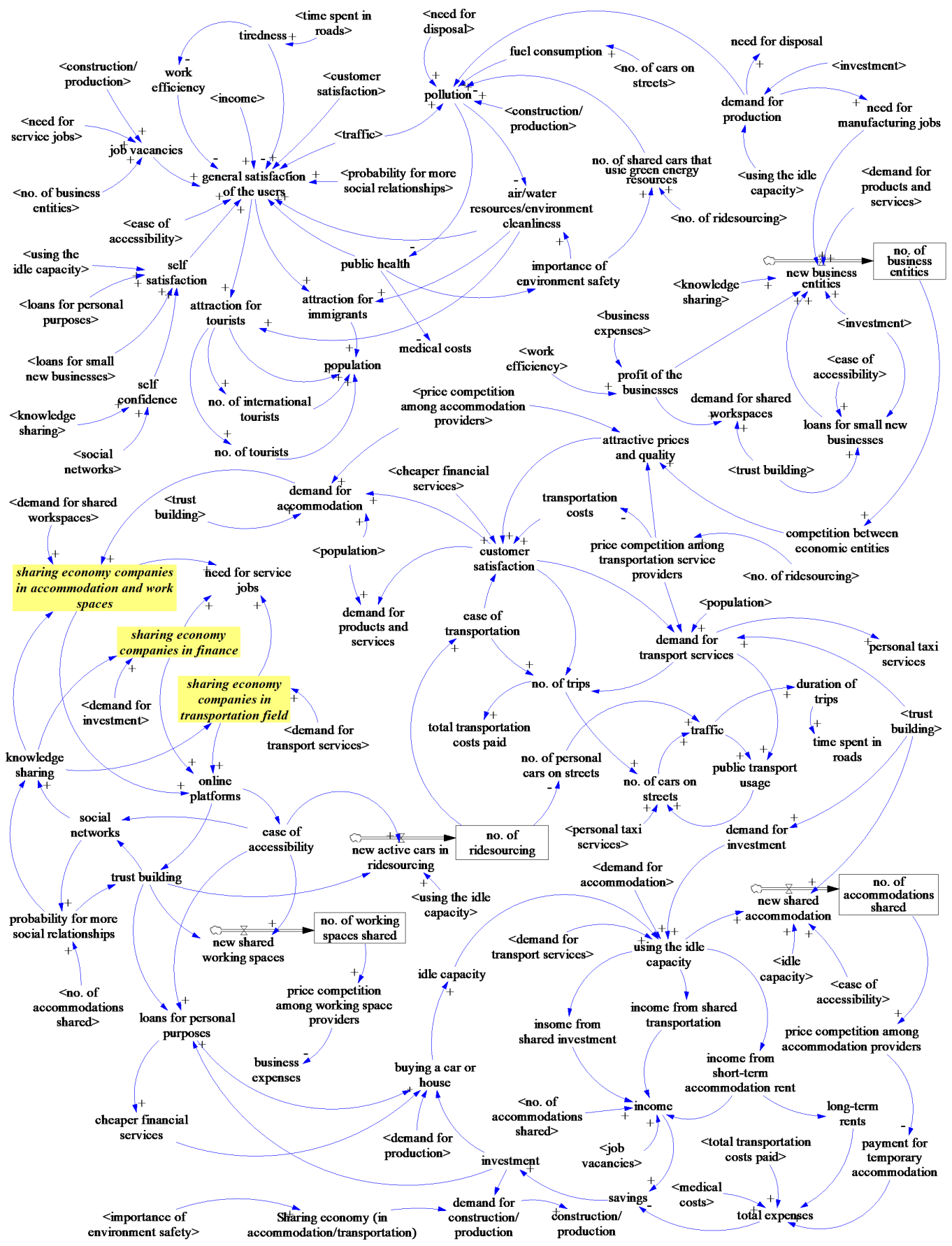




\section{Conclusion}

In the last years, attention has been paid to environmental, social and economic aspects of the sharing economy, as for instance by Frenken and Schor (2017). However, the precise interconnections between SE activities and sustainability have not been thoroughly studied. In this paper a CLD was developed to show a deeper insight into the complexity characterizing SE activities and its relationships with triple bottom lines, which can help us decide on the most suitable strategies to guarantee sustainability. Reinforcing and balancing loops in this diagram indicate the natural interactions between the subsystems and also the subsystem variables.

Our modelling suggests that the expansion and development of SE activities in the society increases the competition among SE entities and capitalist companies from economic point of view. The main driver in this regard is the online platform provided by SE companies that can also pave the ground for further changes, including significant social changes. Besides, the change in the consumption pattern of the consumers in SE affect the environment, through an impact on pollution. In this regard, the rebound effect should also be considered.

Therefore, the interconnection between SE and sustainability pillars, which are touched upon in this paper can shed light on the recent changes in today's economic activities to help decision makers grasp the opportunities and overcome challenges. Current and potential participants in the SE activities, legislative authorities, various NGOs, and businesses in different fields of activity can benefit from having such analysis in mind, which follows system thinking.

However, to more accurately analyse the situation and forecast the outcomes of any change in the system, in the future research, case studies can be considered and system dynamics modeling and simulation for future possible scenarios can be done. The numerical and graphical results of such simulation would provide more accurate insights for the decision makers.

\section{References}

BEKAWADE, V.S., and INGALE, D.R. (2016). «Smart City-Scale Taxi Ridesharing». International Research Journal of Engineering and Technology (IRJET), 3(2), pp.1308-1311

CHO, S., PARK, C., KIM, J. (2017). «Leveraging consumption intention with identity information on sharing economy platforms». Journal of Computer Information Systems.
FRENKEN, K., SCHOR, J. (2017). «Putting the Sharing Economy into perspective». Environmental Innovation and Societal Transitions, 23, pp. 3-10.

GEISSINGER, A., LAURELL, C., OBERG, C., SANDSTORM, C. (2019). «How sustainable is the sharing economy? On the sustainability connotations of sharing economy platforms». Journal of Cleaner Production, 206, pp. 419-429, DOI: 10.1016/j.jclepro.2018.09.196

GOUDIN, P. (2016). The Cost of Non-Europe in the Sharing Economy: Economic, Social and Legal Challenges and Opportunities. Brussels: European Parliament.

GUTTENTAG, D. (2015). «Airbnb: disruptive innovation and the rise of an informal tourism accommodation sector». Current Issues in Tourism, 18(12), pp. 1192-1217, DOI: $10.1080 / 13683500.2013 .827159$

HEINRICHS, H. (2013). «Sharing Economy: A Potential New Pathway to Sustainability». Gaia, 22(4), 228-231.

HOVMAND, P. (2014) Community Based System Dynamics. Springer

KATHAN, W., MATZLER, K., VEIDAR, V. (2016). «The Sharing Economy: Your business model's friend or foe?». Business Horizons, pp. 663-672.

JIN, S.T., KONG, H., WU, R., SUI, D.Z. (2018). «Ride-sourcing, the Sharing Economy, and the future of cities». Cities.

JITTRAPIROM, P., KNOFLACHER, H., MAILER, M. (2017). «Understanding decision makers' perceptions of Chiang Mai city's transport problems- an application of Causal Loop Diagram (CLD) methodology». Transportation Research Procedia, 25, pp. 4438-4453.

KOSINTCEVA, A. (2016). Business Models of Sharing Economy Companies: Exploring Features Responsible for Sharing Economy Companies' Internationalization. M.Sc. Thesis, Norwegian School of Economics, Bergen, Norway.

LIU, Y., YANG, Y. (2018). «Empirical examination of users’ adoption of the sharing economy in china using an expanded technology acceptance model». Sustainability, 10,1262 .

MAANI, K., CAVANA, R. (2007). Systems Thinking, System Dynamics: Managing Change and Complexity. Prentice Hall, Auckland, N.Z. 
MAIR, J. and REISCHAUER, G. (2017). «Capturing the dynamics of the sharing economy: Institutional research on the plural forms and practices of sharing economy organizations». Technological Forecasting \& Social Change, 125 , pp. 11-20.

MARTIN, C., UPHAM, P., BUDD, L. (2015). «Commercial orientation in grassroots social innovation: Insights from the sharing economy». Ecological Economics, 118, pp. $240-251$.

MICHELINI, L., PRINCIPATO, L., IASEVOLI, G. (2018). «Understanding food sharing models to tackle sustainability challenges». Ecological Economy, 145, pp. 205217.

MUNOZ, P., and COHEN, B. (2017). «Mapping out the sharing economy: A configurational approach to sharing business modeling». Technological Forecasting and Social Change, 125, pp. 21-37.

MURILLO, D., BUCKLAND, H., VAL, E. (2017). «When the sharing economy becomes neoliberalism on steroids: Unravelling the controversies». Technological Forecasting \& Social Change, 125, pp. 66-76.

NOVIKOVA, O. (2017). «The sharing economy and the future of personal mobility: New models based on car sharing». TIM Rev., 7, pp. 27-31.

PATER, R. (2015). The sustainability paradox. Retrieved March 5, 2018, from http://the-simple-life.org/the-sustainability-paradox/

PAUNDRA, J., ROOK, L., DALEN, J.V., KETTER, W. (2017). «Preferences for car sharing services: Effects of instrumental attributes and psychological ownership». Journal of Environmental Psychology, 53, pp. 121-130.
RAHIM, N., LEPANJUURI, K., DAY, F., PIGGOTT, H., HUDSON, R., LUBIAN, K. (2017). Research on the Sharing Economy, HM Revenue and Customs: London, UK.

RANJBARI, M., MORALES-ALONSO, G., CARRASCO-GALLEGO, R. (2018). «Conceptualizing the Sharing Economy through Presenting a Comprehensive Framework». Sustainability, 10(7), 2336, doi:10.3390/ su10072336

ROH, T. (2016). «The Sharing Economy: Business Cases of Social Enterprises Using Collaborative Networks». Procedia Computer Science, 91, pp. 502-511.

STANKOVIC, J., KORDIC, N., DRASKOVIC, S. (2016). «Influence of Peer-to-Peer Based Exchange on Creating New Business Models». SINTEZA 2016: International Scientific Conference on ICT and E-business Related Research. Belgrade, Serbia.

STEPHANY, A. (2016). The Business of Sharing - Making it in the New Sharing Economy. New York: Palgrave Macmillan.

STERMAN, J. (2000) Business Dynamics; System Thinking and Modeling for Complex World. Mc Graw-Hill Companies.

VERBOVEN, H., and VANHERCK, L. (2016) «The sustainability paradox of the sharing economy». uwf, 24, pp. 303-314, DOI 10.1007/s00550-016-0410-y. 